EDITORIAL

\title{
Avenues for the Primary Prevention of Breast Cancer in the Second Millennium
}

\author{
Salim M. Adib, MD, DrPH \\ Professor of Epidemiology and Public Health \\ American University of Beirut, Lebanon.
}

Correspondence to: E-mail: sa193@aub.edu.lb, ORCiD: 0000-0001-8831-2954

Breast cancer (BC) has recently surpassed lung cancer as the most frequently diagnosed cancer worldwide, with an estimated 19.3 million new cases and almost 10 million deaths occurring in 2020. A steady ascension in $B C$ incidence has been a remarkable feature in cancer epidemiology for almost a century, and has been reported in richer as well as poorer communities all over the world. This trend is no doubt associated with the ageing of the global population: "Each one-year increase of population ageing (is) associated with a nearly $1 / 2$ year increase of age at $B C$ diagnosis. Population demographics explain forty-two percent of the age variance for $\mathrm{BC} .{ }^{\prime 2}$ The association with global ageing is obviously not amenable to preventive interventions, but many other avenues exist, to modify risk factors leading to $B C$. Less than $1 \%$ of all $B C$ cases occur in men, therefore, this paper will be limited to those avenues likely to prevent $\mathrm{BC}$ incidence in women only. 3

Besides ageing, another known BC-specific risk factor that is not always avoidable is the increase in breast tissue exposure to estrogen, itself associated with changes in patterns of the reproductive life of contemporary women. Improvement in women's socioeconomic status all over the world has led to delays in age at first pregnancy and decreased parity and breast-feeding intensity, which have prolonged the lifetime physiological exposure to estrogen. ${ }^{1}$ In contrast with unavoidable sociological changes, age at menarche is a reproductive determinant which may be a good candidate for prevention. Age at menarche has decreased in all girls in the past century, thus prolonging the interval of physiological breast exposure to estrogen. The decrease was first spotted in more affluent nations, and is now being reported also in less developed ones. ${ }^{4-6}$ It has been suggested that better nutrition and early weight gains in younger girls are main contributors to early sexual maturity. ${ }^{4}$

These findings indicate that early intervention to prevent premature weight gain in childhood may be an important avenue for reducing $B C$ risk. Reliable guidelines exist to help parents and educators address the issue of weight control with children while avoiding psychological distress, stigma and body image distortion. Tools are being developed and validated in various cultural contexts to respond to that crucial balancing act. $^{7-8}$

Excess adipose tissue increases estrogen levels also in post-menopausal women. ${ }^{9}$ Weight loss among perimenopausal women has been found to be associated with significant decrease in risk for $B C$ primary incidence, and for recurrence after a primary resection. ${ }^{10}$ There is limited evidence that food items rich in carotenoids and calcium may provide some protection against $B C$, while charred and processed meats contribute to its incidence. Inasmuch as sedentary lifestyles promote weight gain, physical activity can contribute to BC prevention. Many studies have shown that as little as 75 to 150 minutes of brisk walking each week can lower the risk of $B C$ in all women."

Other lifestyle-associated factors may also present important opportunities for primary prevention. Several studies indicate that alcohol raises estrogen levels in the body, in addition to contributing to weight gain. A pooled analysis of data from 53 studies found that for each alcoholic drink consumed per day, the relative risk of breast cancer increased by about 7 percent. In developing countries, where alcohol consumption is less prevalent, its effect on $B C$ incidence is relatively negligible. This same meta-analysis found that smoking, a known risk factor for several types of cancers, has little or no independent effect on $\mathrm{BC}$ risk in women with low or no alcohol use. ${ }^{12}$

In recent years, there has been increased interest in assessing the impact of outdoor and indoor environmental factors on cancer in general, and on $B C$ in particular. Some pollutants are already known to be carcinogens, but those with particular importance on $B C$ are mostly endocrine disrupting compounds (EDCs), whose impact is mediated through alterations of the activity of endocrine tissues. These EDCs include natural estrogen products such as genestien, a compound find in soja, or in industrial products: 
Adib. Prevention of Breast Cancer in the Second Millennium

organochlorine pesticides such as DDT, parabens in hygiene products or the ubiquitous bisphenol A (BPA) found in plastic items of daily use. Pathological mechanisms follow a variety of toxicological or epigenetic paradigms. The pre-existence of some particular mutations, such as $B R C_{1}$ and $B R C 2$, optimize the interaction between these compounds and the genome, leading to changes in mammary tissue development with an increased likelihood of the later development of $\mathrm{BC}$. Genetic research is on-going to identify new genetic markers of environmental vulnerability, while other compounds, and also medical and non-medical radiations, are being tested in vitro and in vivo to elicit their respective contribution to $B C .^{13}$ A full review of modifiable risk factors of $B C$ cannot be concluded without considering the issue of synthetic estrogen prescribed for medical indications. A first link was found with diethylstilbestrol pills (DES) which was prescribed to millions of pregnant women to prevent miscarriages and other complications of pregnancy between 1940 and 1971. The DES was banned after exposure was associated with an increased risk of $B C$ in the mothers and an increased risk of a rare vaginal clearcell adenocarcinoma in daughters exposed in-utero. ${ }^{14}$ Numerous studies have demonstrated an increased risk of $B C$ among current and recent users of oral contraceptives ( $O C$ ), particularly those who have used them for more than 5 years, and initiated use at a young age. $^{15-17}$ Most of what we know about the association between hormone replacement therapy (HRT) and risk for BC comes from the Women's Health Initiative (WHI). This large randomized controlled trial $(N=16,608$ women) was designed to explore the risks and benefits of combined estrogen and progestin HRT in postmenopausal women. The trial had to be interrupted in 2002, 5 years after its initiation and midway within its planned course, when researchers found a significantly increased $\mathrm{BC}$ risk in women in the combination arm. On the other hand, $B C$ risk was decreased in women in the progestin-only arm. ${ }^{18}$ These findings were corroborated in 2003, in the UK Million Women Study (MWS), which reported that the current use of all types of post-menopausal HRT significantly increased the risk of $B C .^{19}$ The implications of these results on HRT prescription practices were drastic.

In conclusion, this review clearly indicates that avenues for primary prevention of $\mathrm{BC}$ are extremely numerous. They include:

1. Behavioral change regarding healthy diet, physical exercise, alcohol intake and weight control.

2. Changes in clinical practices of OC and HRT, and better counseling during gynecological visits.
3. Legislation to decrease the exposure of populrations to known carcinogens, and to modify industrial processes to decrease adverse exposures.

4. Further research into genomic markers of vulnerability especially among women with a family history of $B C$, which may lead to preemptive, tailored gene therapy in the future. ${ }^{20}$

Public health practitioners all over the world are invited to continue their advocacy and lobbying efforts with governments, community organizations and international agencies, to slow down the continuously upward trend in $\mathrm{BC}$ incidence, as we move into a new millennium.

\section{REFERENCES}

1. Sung $H$, Ferlay J, Siegel $R L$, Laversanne $M$, Soerjomataram I, Jemal A, et al. Global Cancer Statistics 2020: GLOBOCAN Estimates of Incidence and Mortality Worldwide for 36 Cancers in 185 Countries. CA Cancer J Clin 2021; 71:209-49.

doi: $10.3322 /$ caac. 21660

2. Bidoli E, Virdone S, Hamdi-Cherif M, Toffolutti F, Taborelli $M$, Panato $C$, et al. Worldwide Age at Onset of Female Breast Cancer: A 25-Year Population-Based Cancer Registry Study. Sci Rep 2019; 9:14111. doi: 10.1038/s41598-019-50680-5

3. American Cancer Society (ACS). Breast cancer in men. 2021. Available at https://www.cancer.org/ cancer/breast-cancer-in-men.html. Updated at 10/30/2021.

4. Wiley AS. Milk intake and total dairy consumption: associations with early menarche in NHANES 19992004. PLoS One 2011; 6:e14685.

doi:10.1371/journal.pone.0014685

5. Rah JH, Shamim AA, Arju UT, Labrique AB, Rashid M, Christian P. Age of onset, nutritional determinants, and seasonal variations in menarche in rural Bangladesh. J Health Popul Nutr 2009; 27:802-7. doi: 10.3329/jhpn.v27i6.4332

6. Abdou LW, Daou KN, Bou-Orm IR, Adib SM. Is menarche occuring earlier among Lebanese girls? Rev Epidemiol Sante Publique 2019; 67:393-6.

doi: 10.1016/j.respe.2019.07.007

7. Damiano SR, Hart LM, Paxton SJ. Development and validation of parenting measures for body image and eating patterns in childhood. J Eat Disord 2015; 3:5. doi:10.1186/s40337-015-0043-5

8. Shoraka H, Amirkafi A, Garrusi B. Review of body image and some of contributing factors in Iranian population. Int J Prev Med 2019;10:19-29.

doi:10.4103/ijpvm.IJPVM_293_18

9. Munsell MF, Sprague BL, Berry DA, Chisholm G, Trentham-Dietz A. Body mass index and breast cancer risk according to postmenopausal estrogen-progestin 
Adib. Prevention of Breast Cancer in the Second Millennium use and hormone receptor status. Epidemiol Rev 2014; 6:114-36. doi:10.1093/epirev/mxt010

10. Chlebowski RT. Nutrition and physical activity influence on breast cancer incidence and outcome. Breast 2013; 22 Suppl 2:S30-7. doi:10.1016/j.breast.2013.07.006

11. Clinton SK, Giovannucci EL, Hursting SD. The World Cancer Research Fund/American Institute for Cancer Research Third Expert Report on Diet, Nutrition, Physical Activity, and Cancer: Impact and Future Directions. J Nutr 2020; 150:663-71.

doi: $10.1093 / \mathrm{in} / \mathrm{nxz268}$

12. Collaborative Group on Hormonal Factors in Breast Cancer. Alcohol, tobacco and breast cancer-collaborative reanalysis of individual data from 53 epidemiological studies, including 58,515 women with breast cancer and 95,067 women without the disease. Br J Cancer 2002; 87:1234-45.

doi: $10.1038 /$ sj.bjc.6600596

13. Gray JM, Rasanayagam S, Engel C, Rizzo J. State of the evidence 2017: An update on the connection between breast cancer and the environment. Environ Health 2017;16:94-155. doi:10.1186/s12940-017-0287-4

14. Titus-Ernstoff L, Hatch EE, Hoover RN, Palmer J, Greenberg ER, RickerW, et al. Long-term cancer risk in women given diethylstilbestrol (DES) during pregnancy. Br J Cancer 2001; 84:126-33. doi:10.1054/bjoc.2000.1521
15. Althuis MD, Brogan DR, Coates RJ, Daling JR, Gammon MD, Malone KE, Schoenberg JB, Brinton LA. Hormonal content and potency of oral contraceptives and breast cancer risk among young women. Br J Cancer 2003; 88:50-7.

doi: $10.1038 /$ sj.bjc.6600691

16. Dai Q, Liu B, Du Y. Meta-analysis of the risk factors of breast cancer concerning reproductive factors and oral contraceptive use. Front Med China 2009; 3:452-8. doi 10.1007/s11684-009-0080-z

17. Kumle M, Weiderpass E, Braaten T, Persson I, Adami $\mathrm{HO}$, Lund E. Use of oral contraceptives and breast cancer risk: The Norwegian-Swedish Women's Lifestyle and Health Cohort Study. Cancer Epidemiol Biomarkers Prev 2002; 11:1375-81.

18. Holmberg L, Anderson H, HABITS steering and data monitoring committees. HABITS (hormonal replacement therapy after breast cancer-is it safe?), a randomized comparison: Trial stopped. Lancet 2004; 363:453-5. doi:10.1016/S0140-6736(04)15493-7

19. Million Women Study Collaborators. Breast cancer and hormone replacement therapy in the million women study. Lancet 2003;362:419-27.

20. McCrudden CM, McCarthy HO. Current status of gene therapy for breast cancer: progress and challenges. Appl Clin Genet 2014; 7:209-20.doi: 10.2147/TACG.S54992 